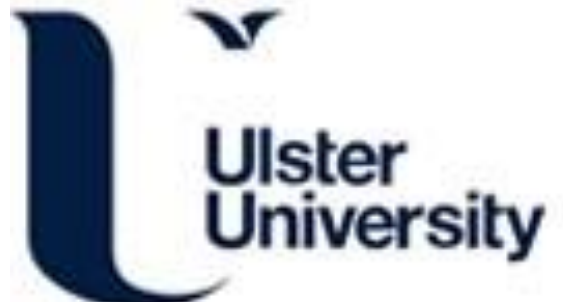

\section{Variability in Constipation Management in Specialist Palliative Care: Findings from a Multi-site Retrospective Case Note Review}

Muldrew, D., Carduff, E., Clarke, M., Finucane, A., Graham-Wisener, L., Hasson, F., McCorry, N., Slater, P. F., \& Mcllfatrick, S. J. (2019). Variability in Constipation Management in Specialist Palliative Care: Findings from a Multi-site Retrospective Case Note Review. Palliative Medicine, (EAPC Abstracts). https://doi.org/10.1177/0269216319844405

Link to publication record in Ulster University Research Portal

Published in:

Palliative Medicine

Publication Status:

Published (in print/issue): 21/05/2019

DOI:

https://doi.org/10.1177/0269216319844405

\section{General rights}

Copyright for the publications made accessible via Ulster University's Research Portal is retained by the author(s) and / or other copyright owners and it is a condition of accessing these publications that users recognise and abide by the legal requirements associated with these rights.

\section{Take down policy}

The Research Portal is Ulster University's institutional repository that provides access to Ulster's research outputs. Every effort has been made to ensure that content in the Research Portal does not infringe any person's rights, or applicable UK laws. If you discover content in the Research Portal that you believe breaches copyright or violates any law, please contact pure-support@ulster.ac.uk. 


\section{Variability in constipation management in}

Unlster University specialist palliative care: Findings from a multi-site retrospective case note review

Muldrew, D.H.L. ${ }^{1}$, Carduff, E. ${ }^{2}$, Clarke, M. ${ }^{3}$, Finucane, A. ${ }^{2}$, Graham-Wisener, L. ${ }^{3}$, Hasson, F. ${ }^{1}$, Larkin, P. ${ }^{4}$, McCorry, N. ${ }^{3}$ Slater, P. ${ }^{1}$ \& Mcllfatrick, S. ${ }^{1}$ (PI).

${ }_{1}^{1}$ Ulster University, UK ${ }^{2}$ Marie Curie Hospice, UK ${ }^{3}$ Queens University Belfast, UK, ${ }^{4}$ University of Lausanne, Switzerland

This work was supported by Marie Curie [grant number ref. MCCC-RP-16-20993]

\section{Introduction}

Constipation is one of the most common symptoms in patients receiving specialist palliative care (SPC), contributing to considerable physical and psychological suffering for patients. Whilst clinical guidelines are available on the management of constipation for people with advanced cancer in specialist palliative care (SPC) settings, the implementation of these guidelines in clinical practice is unclear.

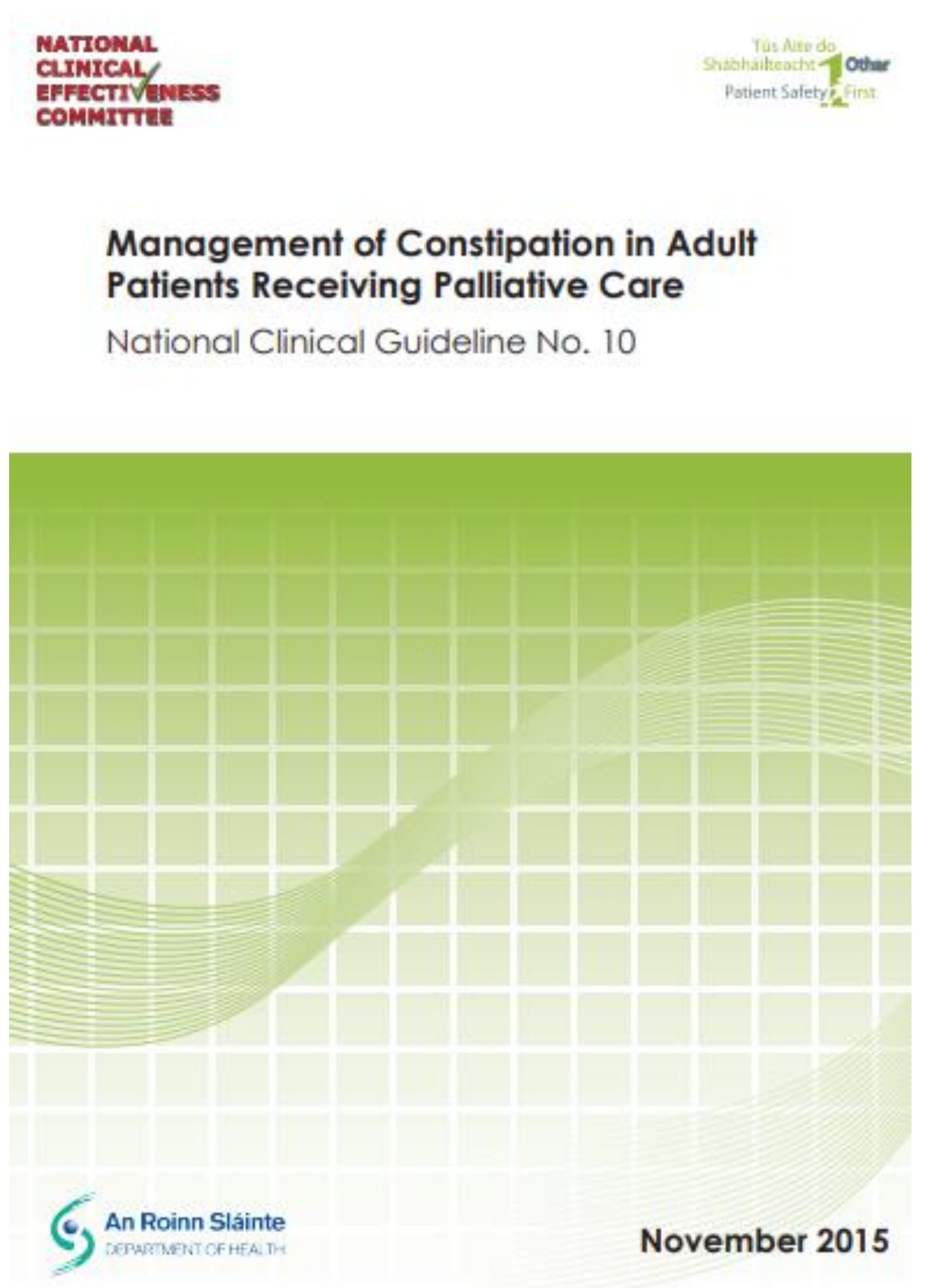

Aim: To examine current clinical management of constipation for patients with advanced cancer in SPC settings

\section{Results}

A physical exam and bowel history was recorded for 109 patients (73\%). Site variations were most evident in multidisciplinary team level of involvement in assessment, patient education on preventative measures, non-pharmacological strategies, and management strategies for opioid induced constipation and bowel obstruction. Sodium docusate and Senna were the preferred laxatives across all sites.

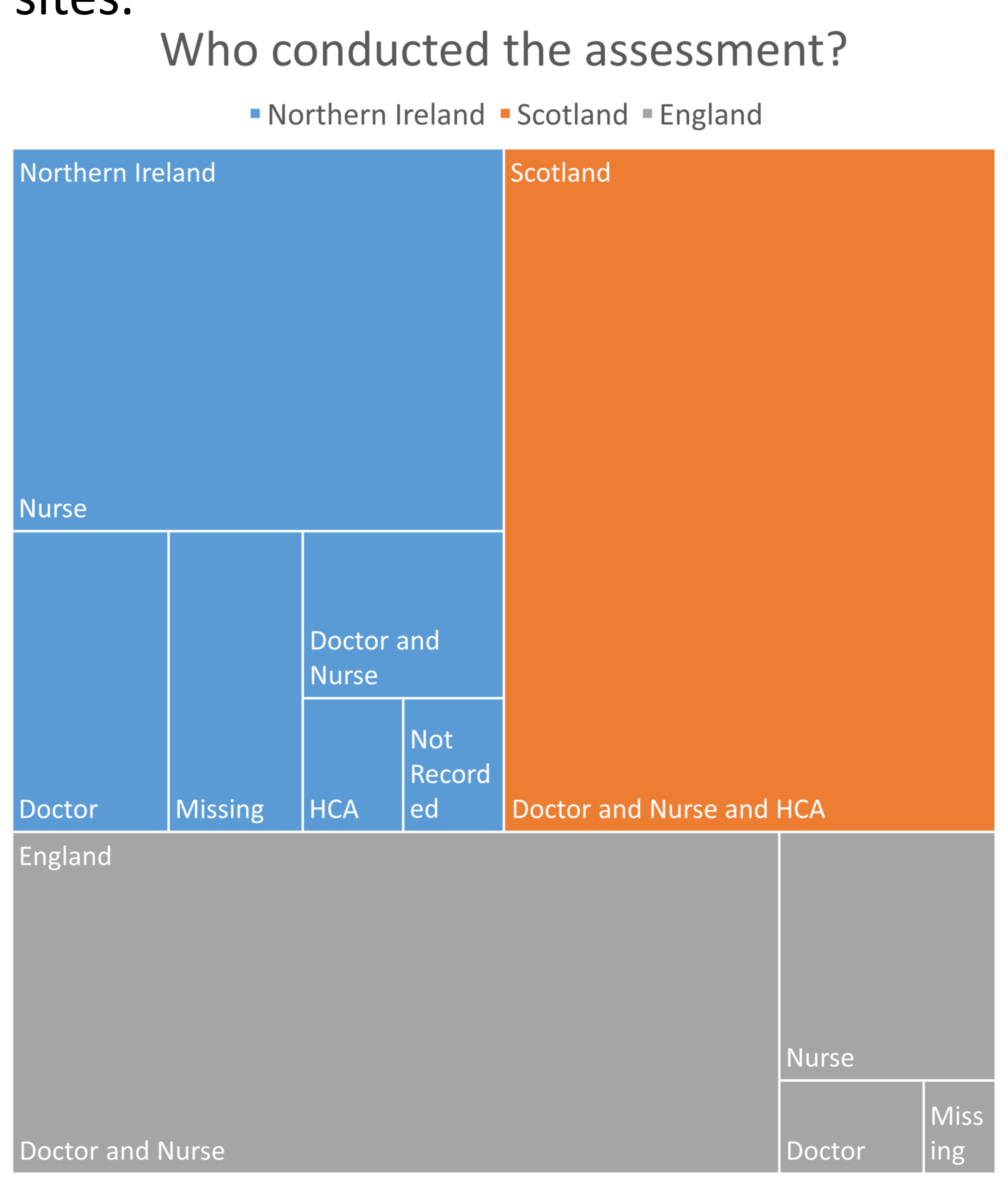

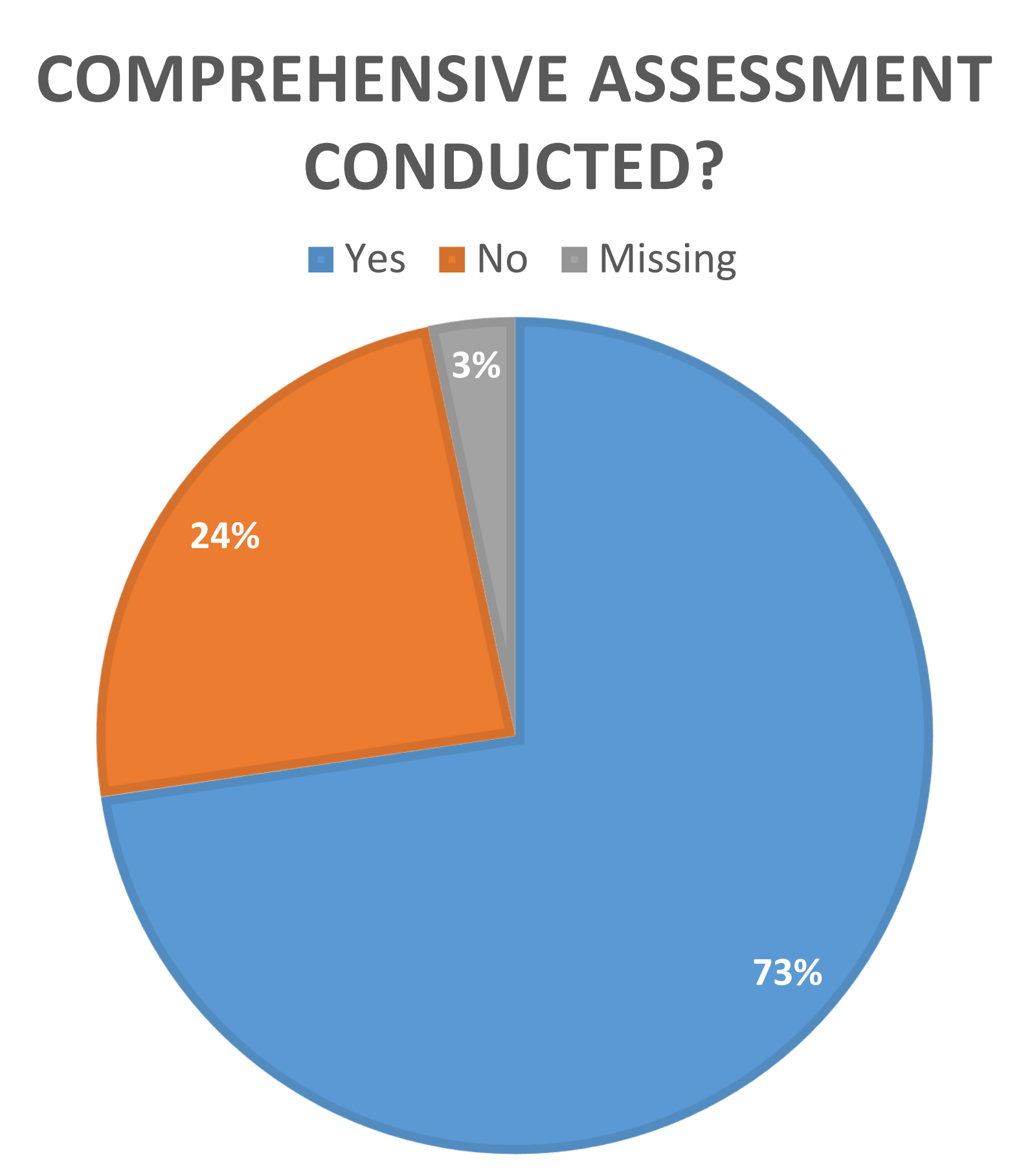

USE OF NONPHARMACOLOGICAL STRATEGIES?

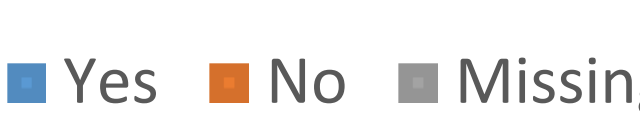

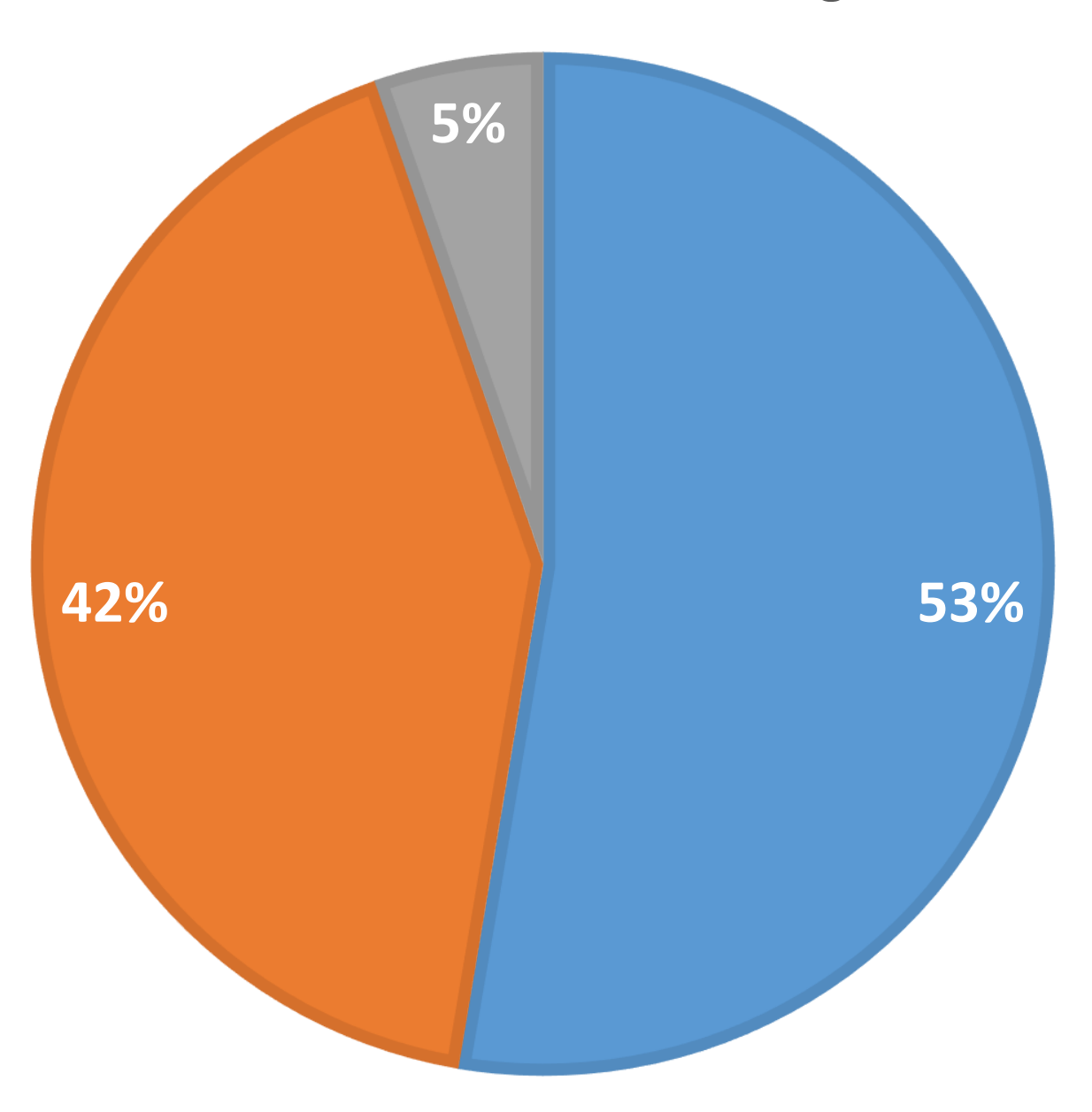

USE OF LAXATIVES? Yes No Not Applicable

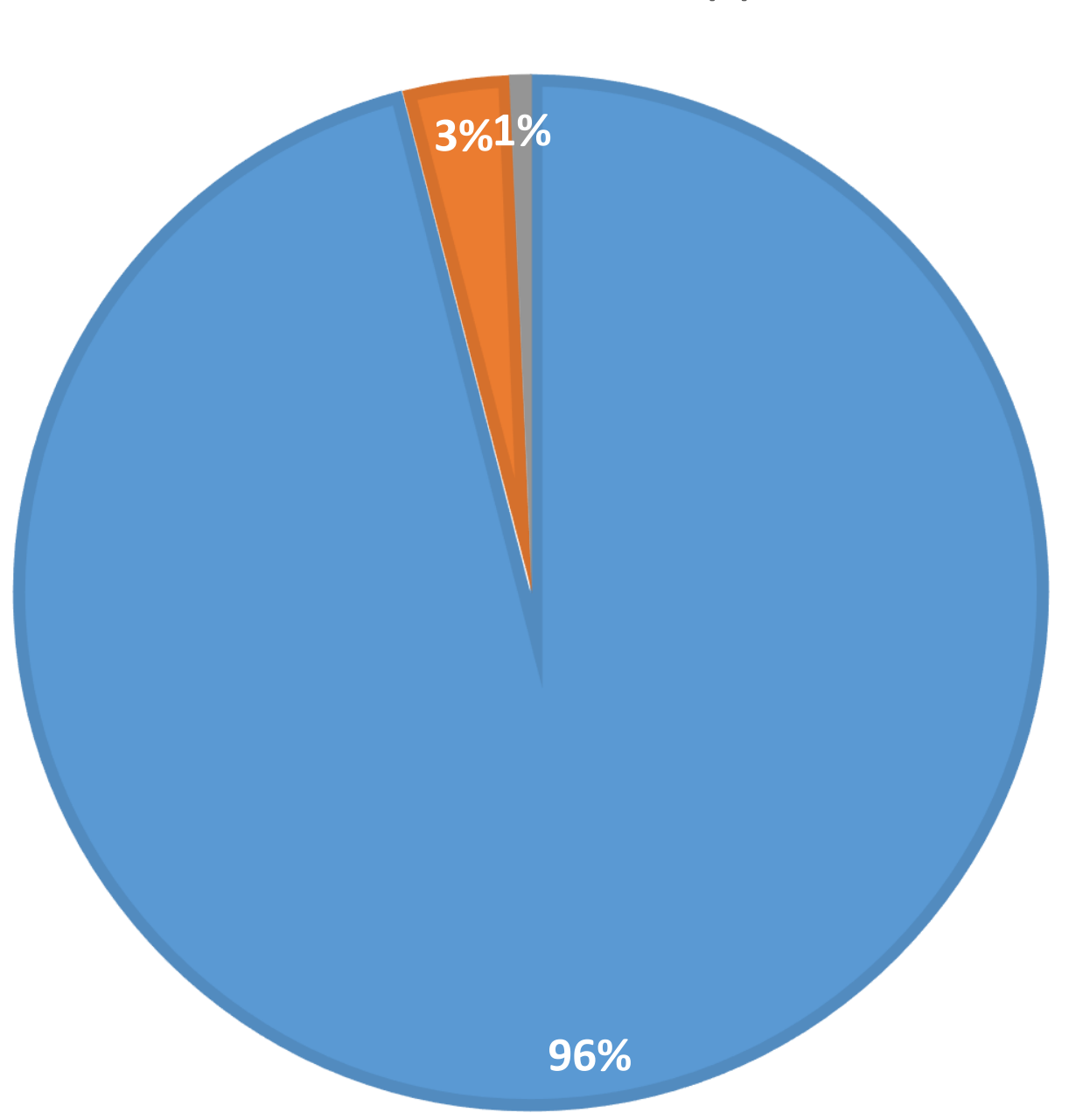

\section{Methods}

A multi-site retrospective casenote review was undertaken, consisting of 150 patient casenotes from three SPC units across the United Kingdom between August 2016 and May 2017. Descriptive statistics were used to compare clinical practices across three SPC sites.

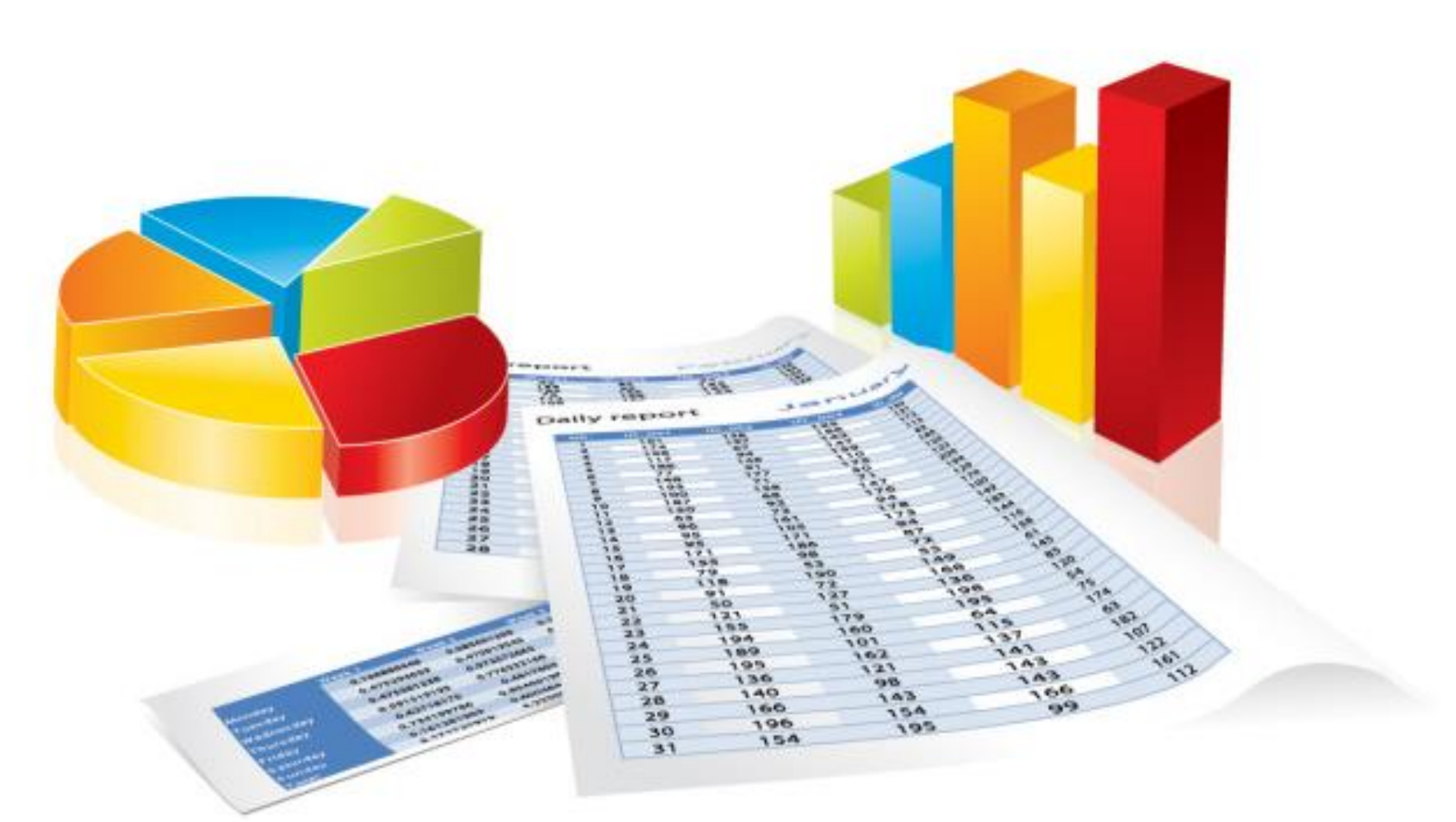

\section{.}

